\title{
A Positive Conversion of Hormone Receptor Status Might Improve Survival after Liver Resection for Breast Metastases: Reply to Dr. Altundag
}

\author{
Giorgio Ercolani \\ Department of Medical and Surgical Sciences, University of Bologna, Bologna, Italy
}

I wish to thank Dr. Altundag for his comment [1]. Recently, several reviews and meta-analyses have pointed out the possibility of discordance between estrogen, progesterone and HER2 status between primary tumours and metastatic disease. Yeung et al. [2] reviewed 47 studies with 3,384 patients and showed that discordance rates were 14, 21 and $10 \%$ in estrogen, progesterone and HER2 status, respectively. In the recent meta-analysis by Schrijver et al. [3] including 39 studies, a conversion rate from negative receptor status in primary tumours to positive status in metastatic sites was found to be varying and was in the range of 9.5-21.5\% depending on the type of hormone receptor.
In the discordance cases, it is more frequent to have HER-2-positive conversion in metastatic sites with negative primary tumours than the opposite [4].

Since the conversion from negative to positive receptor status might affect the type of chemotherapy regimens and longterm prognosis, large prospective studies are needed to evaluate this impact on survival.

In our series, we could evaluate the hormone receptor status in primary and secondary tumours only in 7 patients; 5 of them showed complete concordance, while 1 patient had conversion from negative estrogen and progesterone to a positive status in metastatic disease and the other patient showed a strong conversion to positive HER2 in the metastatic tumour [5]. The number of cases was too small for us to perform full-fledged analyses and to arrive at definitive conclusions. However, the possibility of a conversion from negative to positive receptor status might increase the therapeutic armamentarium against distant metastases and give more value to the combined surgical and chemotherapeutic approach.

Therefore, reassessing the receptor status in metastatic sites is strongly recommended before making a final decision with regard to treatment strategy; a conversion to positive status encourages the use of aggressive, combined therapies.

\section{References}

1 Altundag K: A positive conversion in HER2 status might affect survival after liver resection for breast cancer metastases. Dig Surg 2018, DOI: $10.1159 / 000487606$.

-2 Yeung C, Hilton J, Clemons M, et al: Estrogen, progesterone, and HER2/neu receptor discordance between primary and metastatic breast tumours-a review. Cancer Metastasis Rev 2016;35:427-437.

Schrijver WAME, Suijkerbuijk KPM, Van Gils $\mathrm{CH}$, et al: Receptor conversion in distant breast cancer metastases: a systematic review and meta-analysis. J Natl Cancer Inst 2018, Epub ahead of print.
Rossi S, Basso M, Strippoli A, et al: Hormone receptor status and HER2 expression in primary breast cancer compared with synchronous axillary metastases or recurrent metastatic disease. Clin Breast Cancer 2015;15:307-312.

5 Ercolani G, Zanello M, Serenari M, et al: Tenyear survival after liver resection for breast metastases: a single-center experience. Dig Surg 2018, Epub ahead of print.

\section{KARGER}

(c) 2018 S. Karger AG, Basel

E-Mail karger@karger.com

www.karger.com/dsu
Giorgio Ercolani

Department of Medical and Surgical Sciences, University of Bologna Sant'Orsola Hospital, Via Massarenti, 9

IT-40138 Bologna (Italy)

E-Mail giorgio.ercolani2@unibo.it 